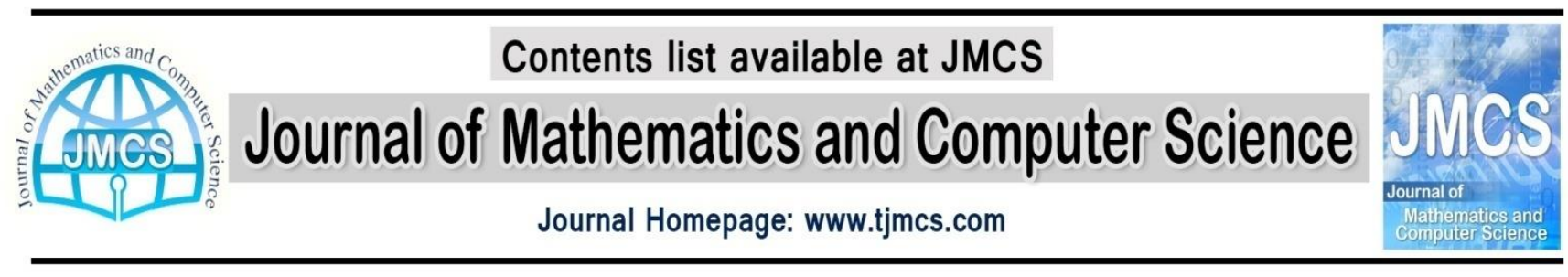

\title{
Designing and Implementing the Higher Education Development Fuzzy Expert System in Iran
}

\author{
Shahin Homayoun Arya ${ }^{1}$, Mahmood Abolghasemi ${ }^{2}$, Ali Mohammad Ahmadvand ${ }^{3}$, Ebrahim Salehi Omran ${ }^{4}$ \\ ${ }^{1}$ Shahid Beheshti University, Tehran, Iran, Faculty of Education and Psychology \\ S_Arya@sbu.ac.ir \\ ${ }^{2}$ Shahid Beheshti University, Tehran, Iran, Faculty of Education and Psychology \\ M_Abolghasemi@sbu.ac.ir \\ ${ }^{3}$ Imam Hossein University, Tehran, Iran, Faculty of Engineering \\ Alimohammad.Ahmadvand@gmail.com \\ ${ }^{4}$ Mazandaran University, Babolsar, Iran, Faculty of Humanity and Social Science \\ edpes60@hotmail.com
}

Article history:

Received May 2013

Accepted June 2013

Available online June 2013

\begin{abstract}
Due to the fact that the quantitative development in higher education requires, on one hand, macro investments and challenges in order to provide new resources and making capacity, and on the other hand requires setting goals and long qualitative activities so that it shall not lead to reverse results; therefore, this matter should be conducted by programming and paying comprehensive attention to different aspects and indexes and this matter has caused educational and providential programming in the higher education future development to become inevitable.

The goal of this paper is to design a fuzzy expert system for the quantitative development of higher education in Iran. Seeing as how the issuance of required licenses are conducted intensively at the Ministry of Sciences, Researches and Technology; therefore, this system is able to help as a decisionmaking- aid to the higher managers of this Ministry in making decisions regarding the quantitative development of higher education with regard to many elements such as: the structural space of the university, the number of faculty members, the

University characteristics and facilities by considering the upper hand documents of higher education development. Designing this program consists of six steps. At the first step, the registered criteria are excavated on the basis of analyzing the content of the upper hand documents and distributing questionnaires among the higher education expert. At the second step, the ranges of alterations of lexical items are determined and at the third step they are changed to fuzzy amounts. At the fourth step, the fuzzy lexical base is compiled using the opinions of the experts and in the fifth step the syllogism engine of the programming system is executed and at the final step defuzzification is conducted. Eventually, the programmed system is assessed by the system output examination method and is accredited by case
\end{abstract}


study. The concluded results are implementing and assessing the corroborated system of the accuracy of performance of the programmed system.

Keywords: Higher Education quantitative development, fuzzy logic, fuzzy expert system

\section{Introduction}

Nowadays Higher Education institutions and universities play an essential role in the development of countries and any kind of discussion and programming on the subject of development in the country without taking into consideration the share of specialized human resources and disregarding it in the added value of different economical, industrial, cultural and etc. sections, will without a doubt go wrong. Therefore, making efforts in order to develop higher education and increase educated forces and promoting the level of technical knowledge and raising the level of higher education in the world and considering these elements in the development of countries seems necessary [1].

During recent years, the fast and ever-going growth in availability of higher education in many countries has been supported as the answer to social, political and economical necessities. This policy caused higher education to be massively noticed by many as the central point which guarantees the development of societies in other fields. Therefore, countries set out to develop their higher education system as much as they could. As a consequence, the countries of the world comprehending the importance of higher education, led to the development of the higher education system being placed as the top priority of educational policies and so the number of the university students of the world increased from thirteen million people in 1960 to 13 times more which is about 165 million people in 2009 [2].

The Islamic Republic of Iran has also taken important steps along with other countries of the world in developing higher education in the country and so during the last 10 years the population of university student has grown to 2.75 times more, from one million and six hundred thousand people in 2001 to more than four million and four hundred thousand people in 2012 [3].

On the other hand, many problems and obstacles exit in the way of the quantitative development of the state higher education, such as existence of the centralized structure of the government and not benefitting from the cooperative management system, not having long- term and strategic programs in university development, paying less attention to the media, internal abilities and capabilities and local and environmental circumstances of the universities, paying little attention in observing the scientific regulations and criteria in establishing university majors, not paying attention to complications, interactions with the surrounding world and various functions of the university [4], applying personal and partial tastes, relative instability and insecurity in the educational rules and regulations, managements, programs, non- application of knowledge engineering, inconsistency in ratifications related to development of higher education with country requirements, lack of proportionality between qualitative and quantitative development of educational majors in universities, and also lack of optimum use of the knowledge of higher education experts and also information technology in this field (logistic document of Iran higher education, 2011). Profiting from information technology and systems based on knowledge can be dominant on a part of the mentioned problems and limitations. The goal of this 
project is designing and creating a fuzzy expert system as a decision- making- aid for the development of higher education in the state. So that based on an analytic, systemic and comprehensive approach and relying on the supervision of the higher education experts of Iran and applying technology and technical equipment based on knowledge, purposeful action can be taken towards development of higher education in the country.

\section{Review of Literature}

Expansion and development of higher education in different countries and societies based on different theoretical models have been investigated. These hypotheses include Functionalism, the Human Capital Theory, the Social Capital Theory, the Cost Benefit Theory, the Public Choice Theory, the Conflict (controversy) Theory and the Feminism Theory [5].Development of higher education in Iran is composed of two aspects of individual (capital) location and social (capital) location which are concluded from the two basic theories of social capital and human capital. These elements can be recognized as a reason of the social request growth to enter higher education and consequently a reason for the quantitative development and growth of higher education in the state.

Most researches of social sciences emphasize on the role of civil norms and networks in the definition of social capital[6]. Social capital is usually viewed as a private and group welfare (Putnam, 2000). In 2001, Davies14, proposed the Neo-Marxist theory in relation to this concept which emphasized on availability of resources and the matter of power in the society. While Coleman believed that social capital is defined based on its function and does not have a separate and independent identity, but it had different identities which have common characteristics. All these identities consist of some aspects of social structure which ease some of the individual actions which are inside the structure. He believes that social capital like other capitals is productive and is not exchangeable like physical and human capitals [7]. Putnam analyzes that the society is measured by the properties of higher levels of the social capital with indexes such as quality of social relations, level of trust and existence of communicational networks. For example, in a society in which there exists more cooperation in the social life or cooperation of parents in the upbringing of the children, the members are going to be more blessed in upbringing and social deviations are going to be less[8]. The existence of the word "social" in the concept of social capital emphasizes that these resources are not individual or personal assets. These resources are in the relation network. Human capital consists of what you know (the total of recognitions, skills and experiences), but social capital depends on who you know and have relations with (the mass of these relations, its quality and variety of the relation network of the individual). The word "capital" also emphasizes that social capital is productive, like human or financial capital. This capital enables the human being to produce value, do something, reach a goal, execute a mission and play a role in the world. And so, no individual can achieve success without social capital (Haman).

Several studies conducted during recent years by Iranian researchers are an indication of the necessity of higher education development and the increasing access to higher education for younger people and know it as influenced by the human capital theory and the social capital theory and recognize it as a social-economical necessity in programming the development of higher education and education of 
specialized human resources and mention it as a movement towards achieving a knowledge- based society.

[9], in a paper titled "The Evolution of New Political, Cultural and Social Institutions and Their Effect on Social Request" examines the interactional relation between the evolution of political, cultural, social and economical institutions by presenting higher education and social request. [10], in his paper titled "The Examination of the Role of Human Capital in Economical Growth: investigates the growth theory based on human capital for economy of Iran during the period of 1997 to 1961 by applying the solo universalized growth model. [11], in designing a research titled "The Assessment of Social Request for Higher Education in Iran During the Period of 2001-2009", has paid attention to predicting social request for higher education during 2001-2011 and detachment of gender and educational groups and has investigated economical and social elements effective on social request for higher education. The results of this research are an indication of the social request to enter higher education is increasing in most higher education subsystems and groups.[12], in an article titled "The Development of Higher Education and Increase of Accessibility: a Necessity" has stated that multiplying the capacity of universities, creating dependant universities and most importantly developing Azad university was able to answer to the social request of the 80 s decade for higher education.[13] in an article titled "The Optimum Capacity of Accepting University Students at Governmental Universities of Iran" with the goal to determine the optimum capacity of accepting university students in the framework of descriptive method and application of a linear programming model and taking into consideration the three main limitations of developing higher education such as the shortage of schools, shortage of physical space and lack of financial resources, has calculated the amount of optimum capacity of accepting university students on the basis of the definition of "criterion student". Homayoon Aria has analytically investigated the development of the subsystems of private - non-governmental higher education institutions and Payam- e- Noor subsystems in two articles. The results of these two projects are an indicator of the times-5 growth of the population of university students of private - non-governmental higher education institutes during the fourth program of state development and the times-300 growth in the number of the university students of Payam- e- Noor university from the time this university was established in $1998[1,14]$.

One of the most important solutions in the programming field is the application of information technology and using expert systems as a decision- making- aid system. The higher education development expert system can be used as a decision- making- aid system by policymakers, programmers and decision makers of the state higher education system, by reconciliation of academic sciences, upper hand documents and using the knowledge of assessors and experts of the state higher education and also profiting from the vast capacity of information systems in programming for development of higher education. Therefore, designing and implementing a fuzzy expert system for the development of higher education is considered as the main goal of this project.

On one hand, with regard to the vastness of different subsystems of higher education such as subsystems of universities and institutes of governmental higher education, Payam- e- Noor university, the Islamic Azad university and etc. and also the existence of different educational levels such as associate degree, bachelor's degree and MA and specialized doctorate and also differences in the role, 
responsibilities and duties between different subsystems and the different dominating facts and regulations on them on the other hand and also limitations of time and resources to conduct this project, led the researcher to design and implement the fuzzy expert system for governmental subsystems and at the supplementary educational course.

The expert system examines different states of an issue by a set of regulations of "if - and then" and then achieves an appropriate result[15]. The fuzzy expert system is a newer copy of the expert system which applies fuzzy logic for processing. In this system, in order to receive inputs and conclude, a set of membership functions and fuzzy rules are used instead of one or zero or absolute logic rules[16]. It seems like applying the fuzzy logic can decrease the risk of making decisions regarding the quantitative development of higher education. In figure 1, the fuzzy expert system model of higher education qualitative development is shown. Based on this model, the designed system will function as a decisionmaking- aid system on the basis of fuzzy logic and input criteria amounts and by using the base of fuzzy regulations and also the knowledge of higher education experts to present a suggestion for the agreement or disagreement with the quantitative development of higher education.

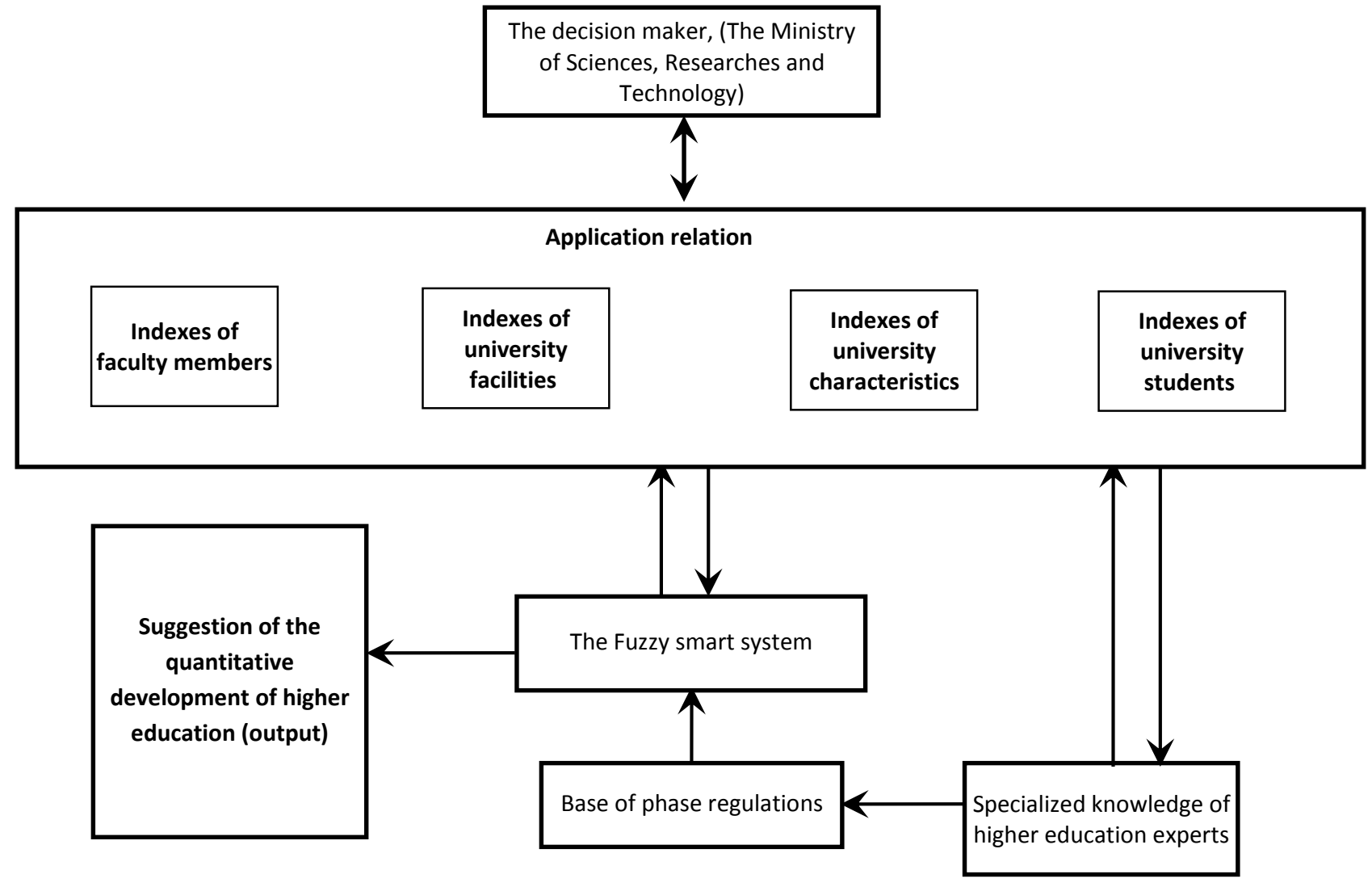

Figure 1: The fuzzy expert system supporting decision- making for the quantitative development of higher education

\section{Designing the fuzzy expert system of higher education development}


With regard to the concepts of designing expert systems, designing different steps, implementing and assessing and accrediting the fuzzy expert system of higher education development are shown in figure 2 and in the following pages the manner of executing each of the steps is explained shortly.

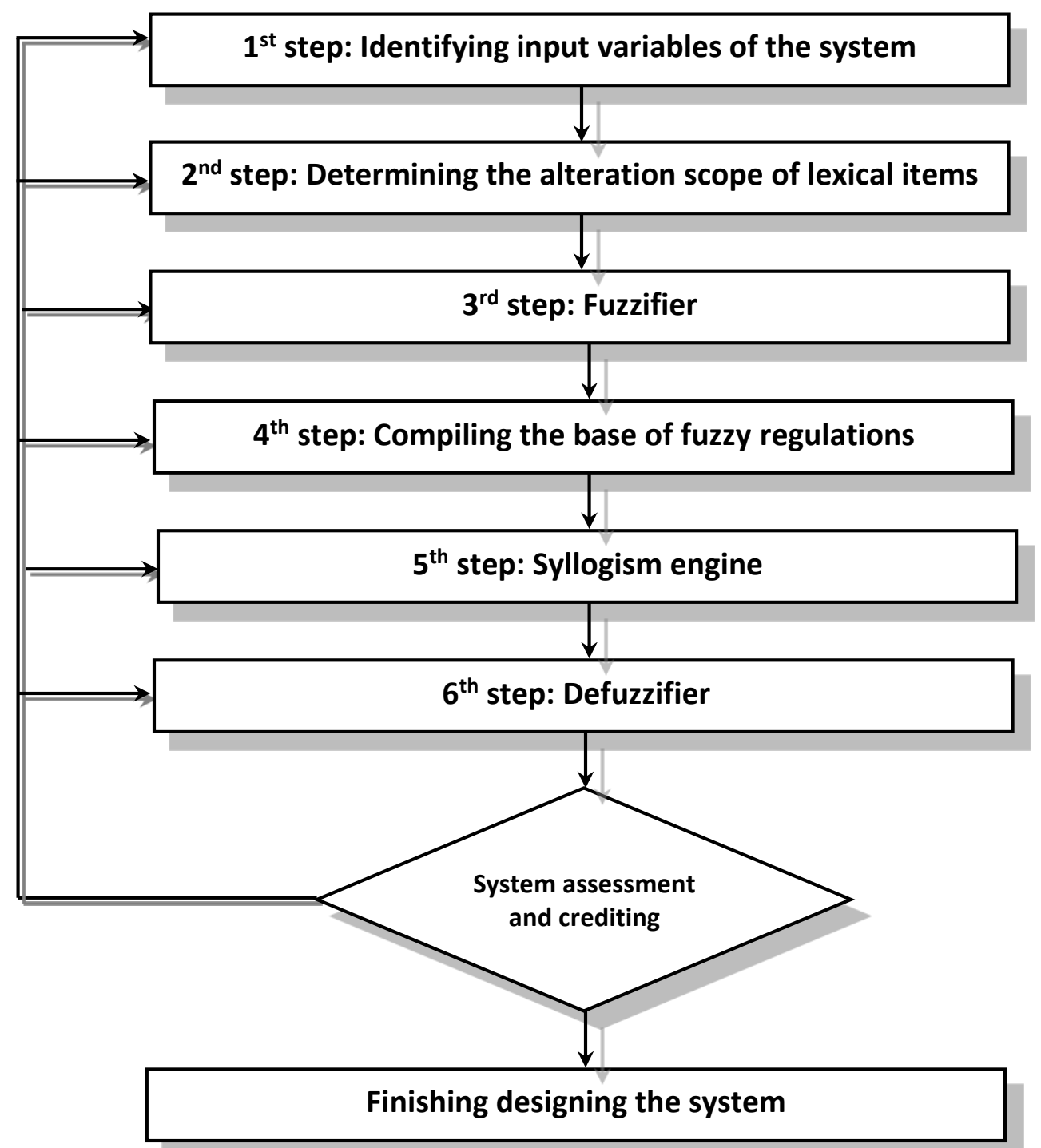

Figure 2: Different steps of designing and executing the fuzzy expert system of state higher education development

In the following pages, the manner of conducting each of the steps is shortly mentioned

First step: Identifying the input and output criteria of the system:

The first step in order to design a system is the determination of inputs of the system meaning finding the important and influential criteria for the quantitative development of higher education. Regarding the fact that making decisions about the quantitative development of higher education is conducted intensively at the Ministry of Sciences, Researches and Technology; therefore, first a thorough and comprehensive study of process, rules, regulations and manner of decision- making of higher education 
development at this Ministry was conducted. Also, the experts of higher education who were employed at this Ministry were questioned by the brainstorming technique regarding the effective criteria on development and 18 criteria were reached. By providing a questionnaire, the extents of the importance of each of the criteria were questioned from the higher education experts. After gathering the information, the criteria which were of less importance from the point of view of the experts were omitted or combined with other similar criteria. Eventually, seven criteria were collected as system input which are: 1- the extent of structural space 2- number of full- time faculty members 3-particulars of the university 4- priorities of the scientifically comprehensive plan of the state 5 - the number of the population of university students compared to the faculty members 6 - the number of faculty members compared to the number of majors 7 - the extent of infrastructure compared to the number of university students. Criteria 1 to 3 are quantitative criteria, criteria 5 to 7 are qualitative criteria and criteria number 4 was extracted upon upper hand documents.

Also, the system output was considered as an agreement with quantitative development or disagreement with the quantitative development of higher education.

\section{Step two: Determination of the scope of criteria of lexical items}

In this step for each of the input criteria the 3 fuzzy states of "good, average and bad" have been considered. In determination of the scope of lexical items, the relations between lexical item criteria and inputs were defined by applying membership functions. At this step, the input amounts are changed into corresponding lexical item criteria of dependency level. In fact, the input criteria are changed into fuzzy amount by the defined membership function. In this project, the triangular membership function has been applied. Seeing as how, any amount of input criteria changes into one of the fuzzy amounts of good, average or bad, based on triangular membership function. Relation 1 and figure number 3 show the specifications of this function.

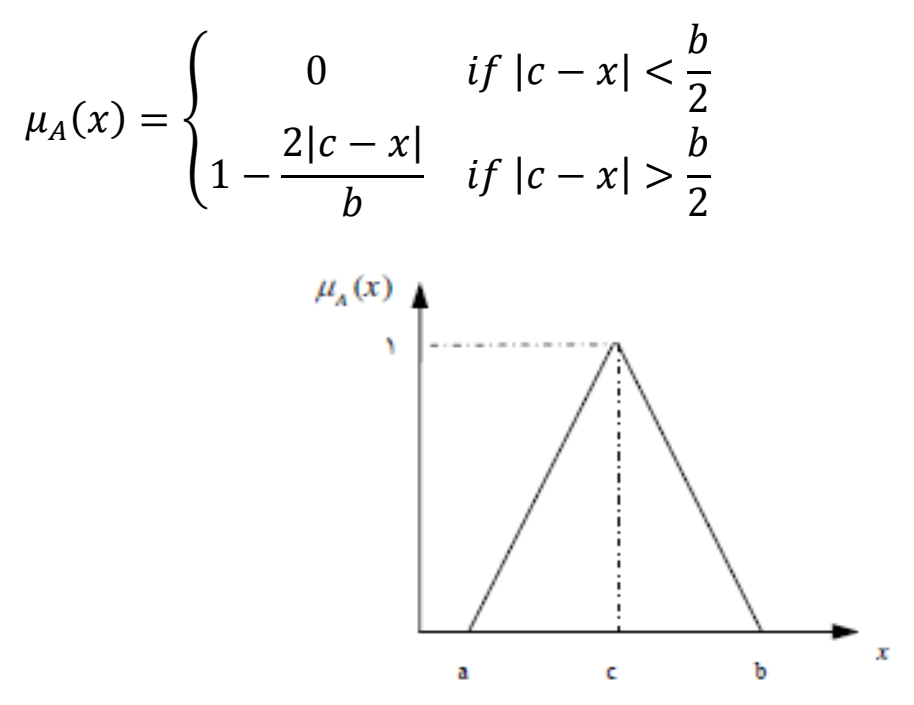

Figure 3: Triangular membership function 
In order to fuzzification the inputs, first each of them were partitioned by using lexical item criteria. Table number 1 shows these lexical item criteria and their equivalent fuzzy numbers. Graphs 4 to 6 show the fuzzy amount for a number of input criteria in graphs. Also, output criteria were partitioned into two lexical item criteria of agreement and disagreement. In graph 7, they are shown graphically.

Table 1: Scope of changes of lexical item of input criteria of the higher education development system

\begin{tabular}{|c|c|c|c|c|c|c|c|c|}
\hline \multicolumn{2}{|c|}{ Bad word } & \multicolumn{3}{|c|}{ Average word } & \multicolumn{2}{|c|}{ Good word } & \multirow{2}{*}{\multicolumn{2}{|c|}{$\begin{array}{l}\text { Scope of lexical items } \\
\text { Input criteria }\end{array}$}} \\
\hline $\mathrm{b}$ & $\mathrm{C}$ & $A$ & $\mathrm{~B}$ & C & $A$ & $\mathrm{~B}$ & & \\
\hline$r \cdots$ & f... & $r \Delta \cdots$ & $\Delta \cdots$ & 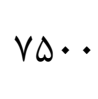 & $4 \ldots$ & $9 \Delta \cdots$ & \multicolumn{2}{|c|}{$\begin{array}{l}\text { The extent of structural space required to } \\
\text { create faculty }\end{array}$} \\
\hline 1 & r & r & 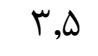 & $\Delta$ & r & 4 & MA & \multirow{2}{*}{$\begin{array}{l}\text { Number of full- time faculty } \\
\text { members }\end{array}$} \\
\hline$r$ & f & 出 & $\boldsymbol{F}, \Delta$ & $\Delta, \Delta$ & $\Delta$ & $9, \Delta$ & $\mathrm{PhD}$ & \\
\hline r & f & r & $\Delta$ & V & $\Delta, \Delta$ & $V, \Delta$ & \multicolumn{2}{|r|}{ properties of the university } \\
\hline r & r & r & $\Delta$ & V & $\Delta$ & $\wedge$ & \multicolumn{2}{|c|}{$\begin{array}{c}\text { Priority of the requested major in the } \\
\text { scientifically comprehensive plans of the } \\
\text { state }\end{array}$} \\
\hline$r \Delta$ & $r \Delta$ & 11 & $r \Delta$ & r. & r & If & \multicolumn{2}{|c|}{$\begin{array}{c}\text { Number of the population of university } \\
\text { students compared to the full- time } \\
\text { assistant professor faculty members and } \\
\text { up }\end{array}$} \\
\hline$r$ & r & $r$ & r & q & r & f & \multicolumn{2}{|c|}{$\begin{array}{c}\text { Number of assistant professor faculty } \\
\text { members and up compared to the } \\
\text { number of supplementary educational } \\
\text { majors }\end{array}$} \\
\hline \& & $1 \cdot$ & $\Lambda$ & 11,0 & If & it & 19 & \multicolumn{2}{|c|}{$\begin{array}{c}\text { The extent of the existing infrastructure } \\
\text { of the faculty compared to the } \\
\text { population of university students }\end{array}$} \\
\hline
\end{tabular}

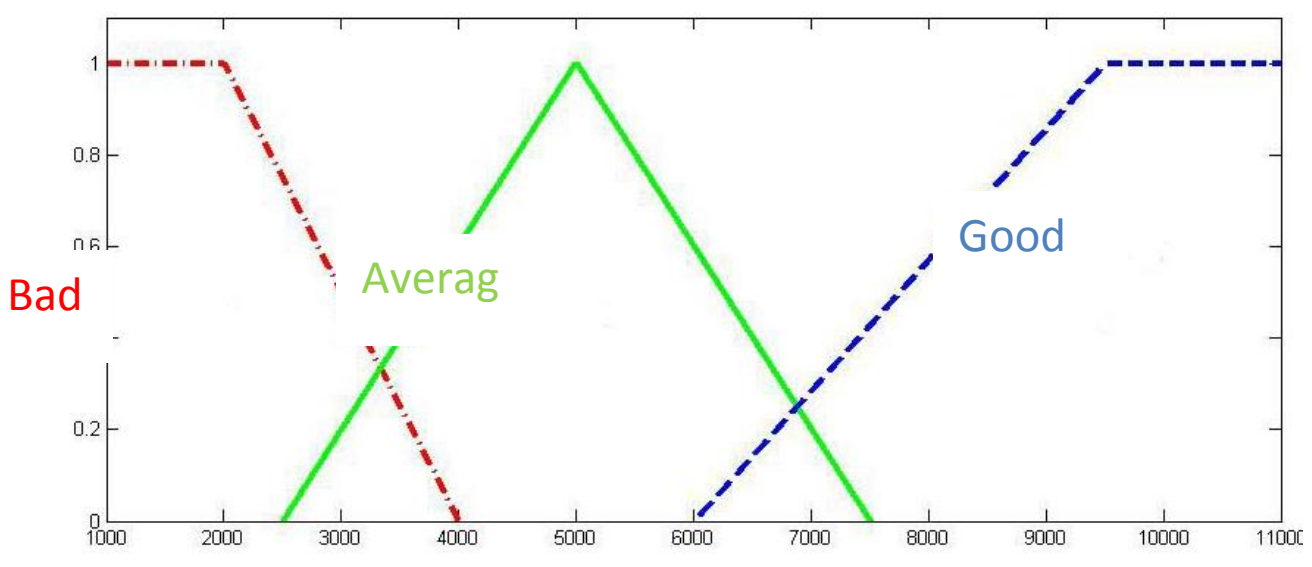


Figure 4: The required structural space extent criteria of creating faculty of higher education quantitative development

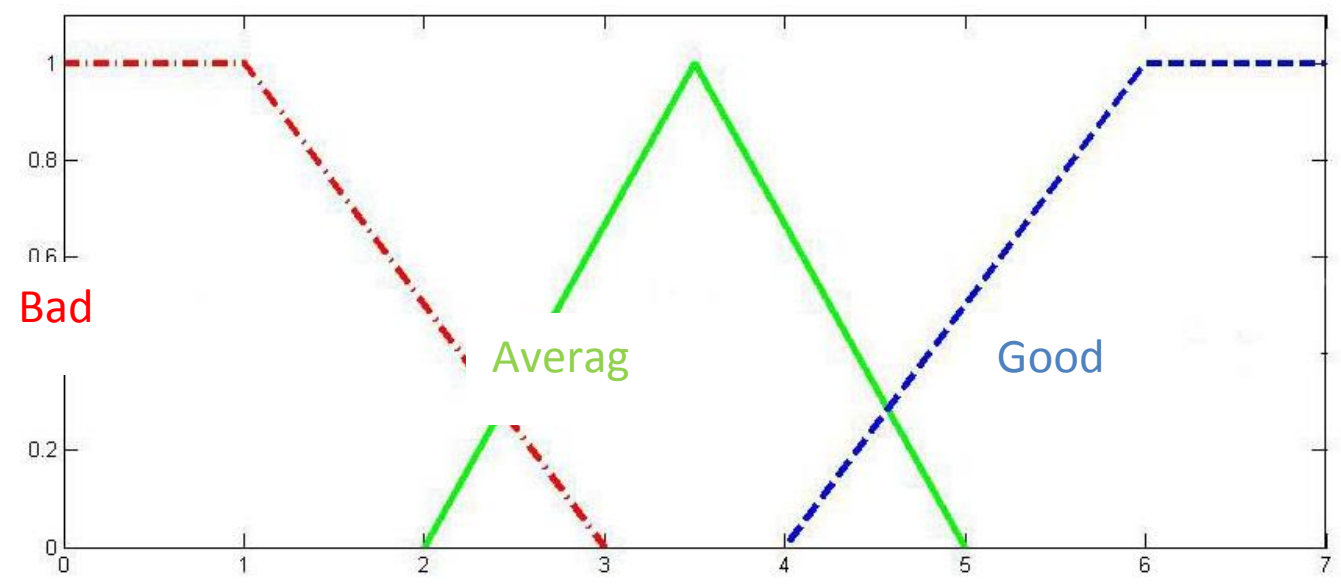

Figure 5: The number of full- time faculty member criteria of higher education development

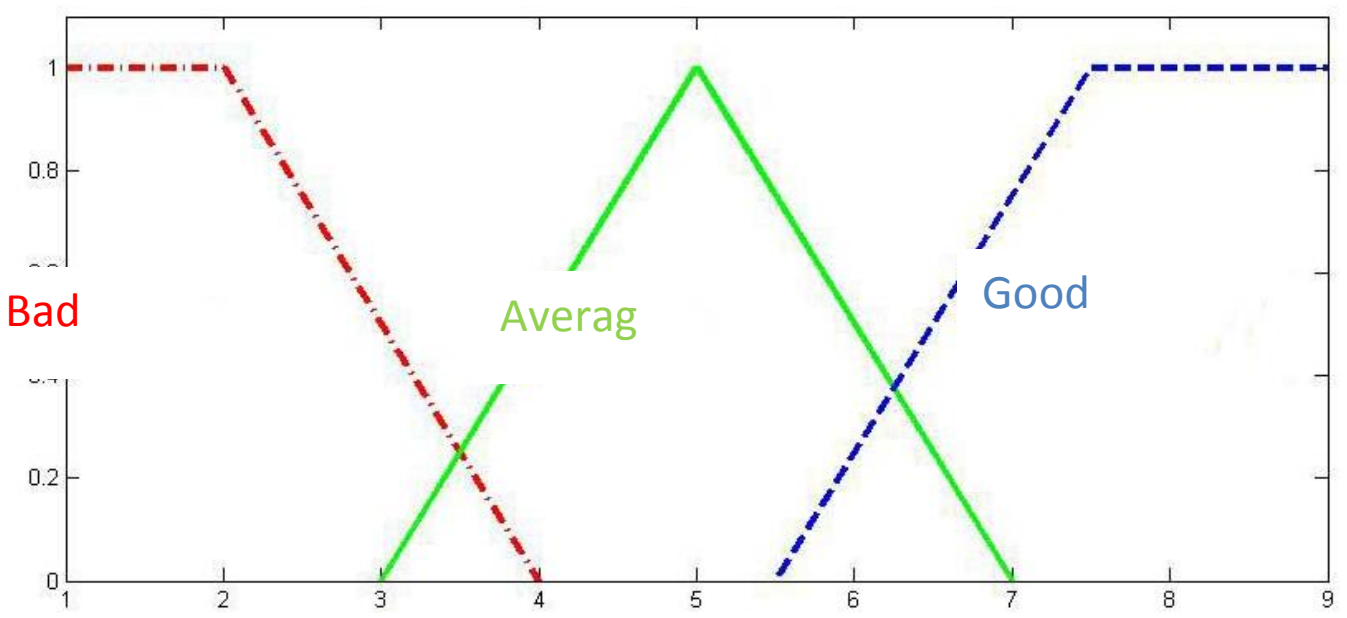

Figure 6: The University properties' criteria of higher education quantitative development system 


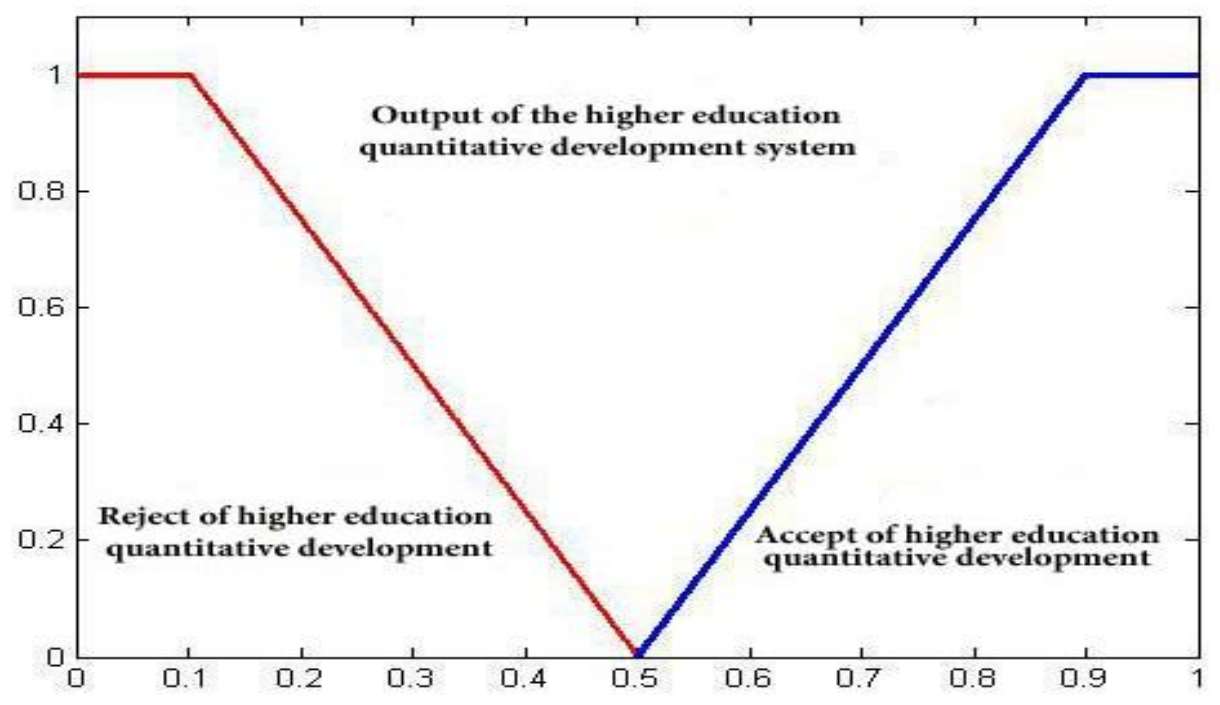

Figure 7: The output of the higher education quantitative development system

\section{Step Three: Fuzzification}

The responsibility of fuzzification is to read the absolute amount of input criteria and altering it to one of the fuzzy lexical amounts existing in rules of the base of fuzzy regulations. Fuzzification should not have a vast calculation volume and it should even have a positive influence on simplifying the calculations related to the syllogism engine (Wang Lee, 2010). With regard to the fact that the information of input criteria of fuzzy expert system of higher education development are absolute and non-disturbing amounts; therefore, singular fuzzification is used in it.

\section{Step Four: Base of Fuzzy Regulations}

The base of fuzzy regulations has been one of the most important sections of the fuzzy system and in this respect that the other parts of the fuzzy system are used in a functional and effective way for implementing these regulations, it is considered as the heart of the system. In the base of fuzzy regulations of the higher education development expert system, ambiguous rules like "if- and then" have been entered from input criteria which were considered before and are effective in the higher education quantitative development. Considering the existence of seven input criteria, each of which have the capability to be described with three lexical items of "good, average and bad", require $37=$ 2187 rules to have a complete set of rules. Which with regard to the lack of time and considering the opinions of higher education experts and also difficulty in the system process, rules which were of little importance and caused waste of time and slowed down the calculations, were not mentioned. Therefore; at the beginning more that 400 rules were written down which after further investigation and consulting with higher education experts became less in number and reached 133 rules. To design the base of fuzzy regulations, composite rules and component " $V$ " were applied. 
Consistency among the rules of the base of rules has been completely observed due to the fact that they were arranged by Excel19 software and the rules which were inconsistence were omitted by consulting the experts. On the other hand, in order to achieve a more efficient extraction of rules, the fuzzy Delphi method was also applied. It was implemented in MATLAV software and a number of these rules have been mentioned in figure 8.

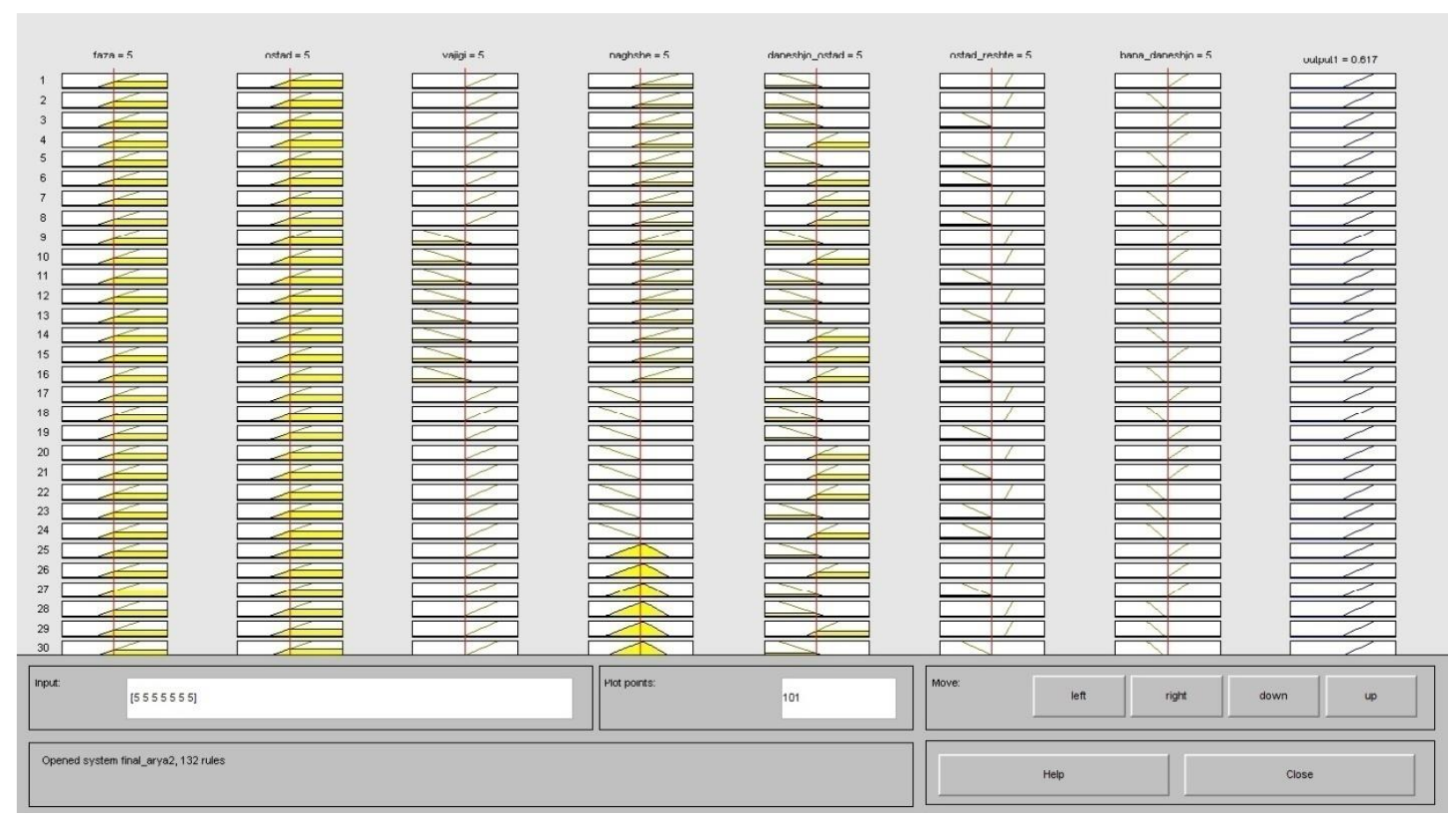

Figure 8: The base of fuzzy knowledge rules created in MATLAB software

19 Excel

\section{Step five: The syllogism engine}

After obtaining the rules and establishing the base of fuzzy rules, we need syllogism engine in order to create proper fuzzy outputs by accepting fuzzy inputs based on the base of rules. Usually overlap exists in the condition section of fuzzy rules. And so there exists a partial accordance between the input criteria membership function with two or three of the membership functions from lexical items. Consequently, it is inferable by two or three rules of the base of rules. Therefore, competition should exist in the syllogism engine so that it will be able to create a suitable output. For this purpose, conclusion based on separate rules have been used due to the fact that the aim is to obtain result from all the rules, each of which have the ability to produce fuzzy output. All the existing rules in the base of knowledge are summarized as a unique relation as "if- and then", while all the rules are assumed independent and therefore social performance has been applied to combine the rules so that it could be conducted conservatively and all rules could be used in the final conclusion. In addition, the final membership function has been calculated by applying the Mamadani combination. 


\section{Step six: Defuzzification}

The criteria entering the higher education development fuzzy expert system are in non- fuzzy and absolute amounts and numbers. But the amounts obtained by the syllogism engine of this system are fuzzy and it is necessary for these amounts to be changed into appropriate non- fuzzy amounts. Input of the defuzzification section is the output of the syllogism engine (the results obtained from rules) that has to be mapped at an absolute point. In defuzzification, we face a vague set which makes reaching a number difficult. This matter makes the work of this section harder than the defuzzification section[17]. In this research, the center of gravity defuzzification, which is very functional and it is mentioned as the best defuzzification is applied.

All mathematical operations to implement the system have been conducted by the FLS equipment box and MATLAB software. As it is seen in the algorithm, after testing the model, if the error of the model is in an acceptable range the process of designing and implementing the system is completely finished; otherwise, the previous steps should be revised and necessary alterations should be made.

The output of the expert system will be a number between 0 to 1 . In case the amount is between 0 to 0.5 , the higher education quantitative development will be disagreed with. The closer this number is to zero, it indicates higher power in making decisions in rejecting the request and non-existence of required indexes and circumstances of development and if this number is between 0.5 to 1 , it indicates agreement with higher education quantitative development and closeness to number 1 , indicates the registered amounts in the system with more power and possibility of creating major and confirms the new course field.

Assessing and accrediting the fuzzy expert system of higher education development Any system which is designed has errors because it does not contain all aspects of the real world. If this error is in a tolerable range the system has partial creditability and otherwise, the designed system should be revised. In order to assess the applied system in designing and implementing the higher educational development fuzzy expert system, the output behavior methods have been used and for accrediting the system, the case study method[18].

\section{System assessment}

One of the methods to assess the designed expert system and be informed of its performance accuracy is the output behavior analysis method. In this method, the amount of the two criteria of increase and decrease input are given by fixing the amount of other criteria. For increase and decrease in inputs, the amount of output is calculated by the expert system. The obtained behavior is analyzed. In case the behavior of outputs is confirmed for the changes in the two input criteria based on the review of literature or opinions of the experts, the creditability of the expert system will be confirmed; otherwise, the expert system should be altered.

In this project, this work was conducted for different inputs. The equivalent outputs of each combination were calculated by using MATLAB software. The outputs were analyzed by experts as well as the researcher. The obtained analysis confirmed the accuracy of outputs. 
Figure 9 shows one case of these behaviors, in the figure axis $X$ shows the structural space criteria and axis $Y$ shows the criteria of the number of faculty members and the vertical $Z$ axis is the axis of output amounts. The enclosed area between the amounts of 0 to 2 from the first criteria and the amounts of 0 to 8 from the second criteria have an output equal to zero. Also the enclosed area between the amounts of 0 to 10 from the first criteria and amounts of 0 to 2 from the second criteria also have an output equal to zero. This output means that weakness in the amount of required structural space and the number of faculty members causes disagreement with the higher education quantitative development. But the more these two criteria increase simultaneously, the system output will lead further towards 1 which means agreement with the development. Therefore the enclosed area between the amounts of 6 to 10 of the first and second criteria show the maximum amount of output which indicated agreement of the designed fuzzy expert system with the higher education quantitative development. Number of full- time faculty members Extent of the required structural Space to create faculty

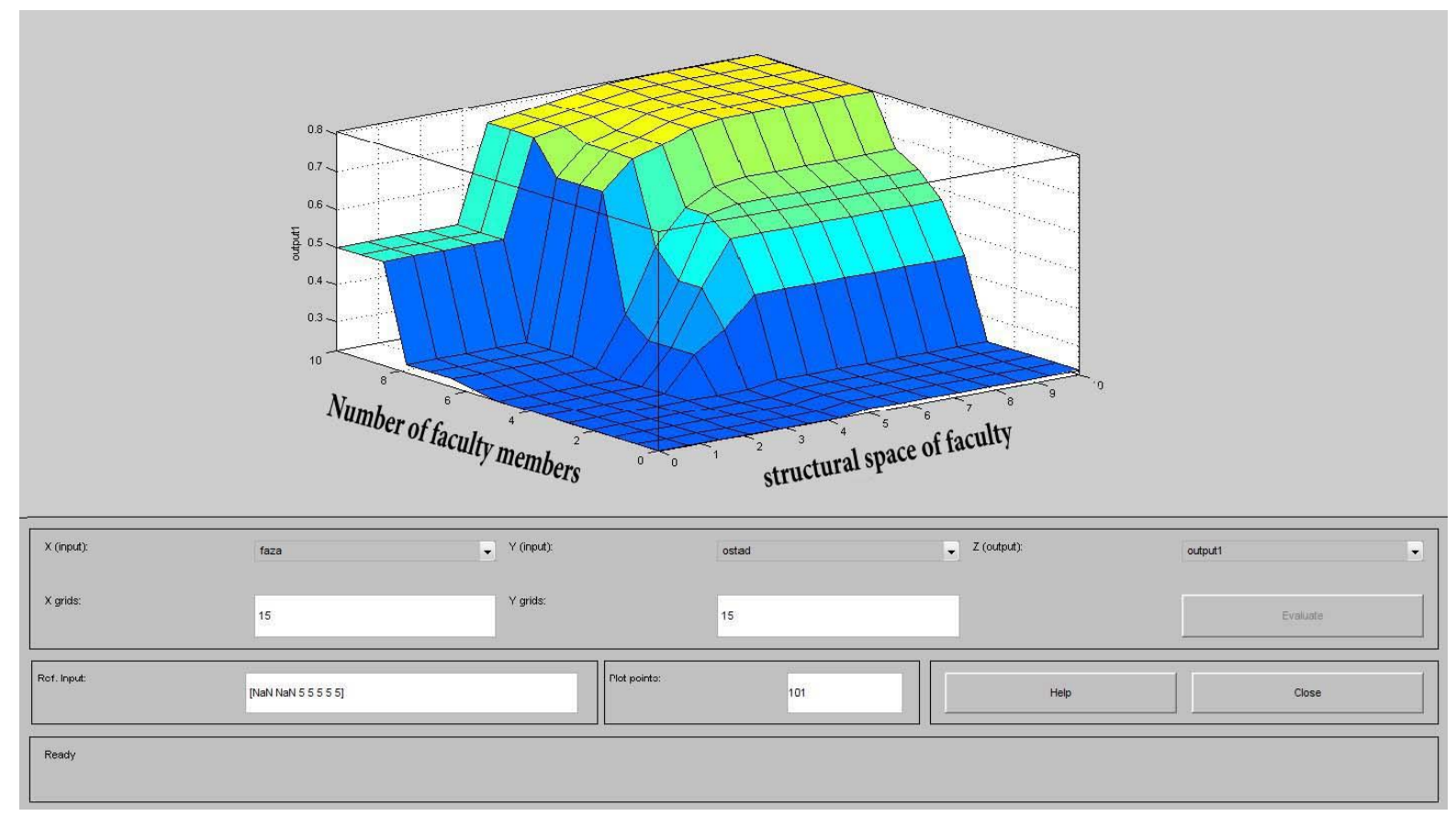

Figure 9: Behavior of the fuzzy expert system with the changes in criteria of structural space and number of faculty members

\subsection{Case study}

In order to accredit the system, the case study method is applied. In this method, the obtained result from the system is compared and adjusted to the real result. In case the results obtained from the system and the real obtained result are in accordance or have minor differences, the accuracy of the function of the system will be trusted and the creditability of the system will be approved[19].

In this project, two cases of university requests for the quantitative development of creating a new course location which possessed suitable and complete data and was presented in the relating 
specialized committees and has taken votes are given to the system as standard inputs and the obtained outputs from the system are compared with the vote and opinion of higher education experts at specialized committees.

It is worth mentioning that the output amount of between 0.5 to 1 are regarded as the agreement of the system with creating a new course location and the amounts of 0 to 0.5 mean the disagreement of the system and incompetence of the university in creating the requested course location. The closer the output of the system is to number 1 or 0 it means the more trust of the system for agreement or disagreement with the establishment of the requested location course by the university.

The first case study:

The Ferdosi University of Mashhad has been an applicant of creating a history field - the history of Iran after Islam major at the specialized doctorate level. The information of input criteria of the expert system is:

1. The structural space of the related faculty is equal to 3500 square meters.

2. The number of full- time faculty members employed at the faculty that have suitable specialty with the requested major are 3 assistant professors and 3 associate professors

3. With regard to the antiquity, privilege of being famous and quality of Ferdosi University of Mashhad, this university has been one of the best universities of the state and the number which was allocated to it for the criteria of properties of the university was number 9 translates as good

4. With regard to the related issues to Iran and Islam in the Humanities and Islamic knowledge groups, it holds the priority of A or first; therefore, the amount of lexical item criteria of the comprehensive plan of the state criteria will be equal to 8 .

5. The criteria of the number of university students compared to the assistant professors and up in the faculty will be equal to 18.92 .

6. The criteria of the faculty members compared to majors has been obtained equal to 2.29.

7. The criteria of the number of university students compared to the physical space of the faculty is also equal to 10 .

After entering the amount of input criteria in the output fuzzy expert system, a number equal to 0.7835 was obtained from the software which means the complete agreement of the system with creating the course location and quantitative development of higher education.

With the conducted investigations by the researcher it was observed that the input criteria possess good and average lexical items and the software output is also in accordance with the analysis and opinion of the experts of higher education. Also the opinion of the respected members of the Humanities Specialized Committee is agreeing with creating the mentioned major. 
The Second Case Study

1. The international Imam Khomeini University of Ghazvin requests the field of mine engineering extraction major at the specialized doctorate level. The required data of input criteria of the system are:

2. The structural space of the related faculty is equal to 4000 square meters.

3. The university has introduced 10 faculty members for creating this major but with regard to the specialty of the introduced professors only 2 assistant professors have an educational field related to the orientation.

4. With regard to the antiquity, capability and quality of the international Imam Khomeini University of Ghazvin, this university has been one of the best universities of the state and the number which was allocated to it for the criteria of characteristics of the university was number 8 which means good

5. With regard to the fact that the subject of discovery and extraction of mineral substances is a part of priority B or second in the technology group of the scientifically comprehensive plan of the state; therefore, the amount of the criteria of state scientifically comprehensive plan is equal to 5 .

6. The criteria of the number of university students compared to the assistant professors and up in the faculty has been calculated equal to 37.31 .

7. The criteria of the faculty members compared to majors has been calculated equal to 2.30 .

8. The criteria of the number of university students compared to the structural space of the faculty is also equal to 3.6.

The conducted examinations show that the criteria of the number of faculty members and also the number of university students compared to professors and the number of university students compared

to the structural space of the faculty possess bad lexical items and the lexical item criteria of state scientific comprehensive plan priority is also average and as a result with regard to the importance of the two criteria of faculty members and the number of university students compared to professors in making decision to create a major especially at the specialized doctorate level and considering the weakness of these two criteria the opinion of higher education experts also shows disagreement with creating the major and is an indication of the accuracy of function of the designed expert system. It is worth mentioning that the opinion of the respected members of the engineering and technical specialized committee was to disagree with creating the requested major.

\section{Result:}

In this project how to design and use a fuzzy expert system of higher education system as a decisionmaking- aid in agreement or disagreement with the request of a university based on the quantitative development and creation of a new course location has been discussed.

The obtained output from the designed fuzzy expert system is based on the input criteria and extracted rules from the upper hand documents and higher education experts, in a manner that the amounts of criteria, fuzzy criteria and base of rules has been completed over time and by confirmation of the higher 
education experts and comparing the obtained results from the system and opinions of the specialized committee, confirm the acceptability of the mentioned system. The designed fuzzy expert system can be used as a multi-tasked decision- making- aid system for other subsystems of the higher education and other levels of education with trivial alterations in the base of rules or input criteria. Applying the fuzzy method to make decisions regarding higher education development has better results from the absolute point of view. Because the fuzzy method with multiplicity of rules, lack of accurate information, uncertainty in decision making and under uncertain circumstances will have better responses. With regard to the suitable number and function of the input criteria of the system in qualifying the qualitative and quantitative circumstances of the university in order to create the new course location and leading the state higher education institutions and universities in higher education development in accordance with the required sciences and technology of the state, using this system can be applied as a solution of purposeful development of higher education in Iran.

Also it is recommended to the higher decision- making managers and directors at the Ministry of Sciences, Researches and Technology to make analytical- systemic, broad- based, knowledge- based, far from prejudice and imposing personal and bias opinions decisions by applying this system and similar systems and relying on information technology equipment in the purposeful development of higher education in the state.

\section{Reference:}

[1] S. H. Aria, et al., "The analysis of the development zone of Payam- e- Noor University until the end of the fourth program," the journal of policy of science and technology, pp. 108-123, (2011).

[2] -. UNESCO, "Enrolment by ISCED levels," Institue for Statistics (2011).

[3] D. s. h. e. journal, "report of compiling the strategic program of the higher education system education domain of basic value basis investigation and land journal," Ministry of Sciences, Researches and Technology (2011).

[4] M. Y. d. Sorkhabi, A review of the investigation of the performance of university systems: Shahid Beheshti Universit, (2001).

[5] E. S. Omran, "theoretical views of higher education; Tehran: two monthly project- scientific newspapers of Shahed University," two monthly project- scientific newspapers of Shahed University, vol. 11, pp. 55-68, (2004).

[6] The Well-being of Nations The Role of Human and Social Capital: The Role of Human and Social Capital: OECD Publishing, (2001).

[7] J. S. Coleman, "Social Capital in the Creation of Human Capital," American Journal of Sociology, vol. 94, pp. S95S120, (1988).

[8] A. Salehi Omran and Y. Mehr Ali Zadeh, "Changes of the work market, social capital and higher education development," series of the resistance development and higher education articles, higher education programming and project institution, vol. 1, (2004).

[9] M. Farastkah, "The evolution of new political, cultural and social institutions and their effect on social request, higher education programming and project institute" (2002).

[10] A. M. Hadian, A. , "Investigation of the human capital role in economical growth," Economy and administrative faculty of Isfahan University, (2002).

[11] M. Gharoon, "Assessment of the higher education social request in Iran in the period of 2001- 2011; higher education programming and project institute," scientific report (2002).

[12] M. H. Abbasi, et al., "development of higher education and increase of access to it: a necessity," in The complete set of the articles of the 51st meeting of the presidents of universities and research and scientific centers, The Ministry of Sciences, Researches and Technolog, (2004).

[13] A. Roshan, "Optimizing the capacity of accepting university students at governmental universities of Iran," The journal of project and programming in higher education, pp. 97-115, (2010). 
[14] S. H. Arya, et al., "the analytical investigation of the development status of non- governmental - private higher education institutions during the fourth program of economical, social and cultural development of the Islamic Republic of Iran (2005- 2009)," The journal of researching the educational systems; the sixth year, pp. 121-158, (2012).

[15] W. Siler and J. J. Buckley, Fuzzy Expert Systems and Fuzzy Reasoning: Wiley, (2005).

[16] C. Matthews, "A formal specification for a fuzzy expert system," Information and Software Technology, vol. 45, pp. 419-429, (2003).

[17] M. Fasanghari and G. A. Montazer, "Design and implementation of fuzzy expert system for Tehran Stock Exchange portfolio recommendation," Expert Systems with Applications, vol. 37, pp. 6138-6147, (2010).

[18] A. B. Zendeh, "compiling a fuzzy expert system in order to design an organizational structure," future of management, pp. 103-128, (2009).

[19] B. Sohrabi, et al., "Designing fuzzy expert system to select programming system of organization resources," Modiriat Sanati publications, vol. 30, pp. 39-58, (2011). 